\title{
PELATIHAN SKILL PENGURUS SANGGAR BACA TRILOGI BERBASIS INTERNET MELALUI SISTEM INFORMASI DESA (SID)
}

\author{
Bagus Kuncoro, Kodrad Budiyono \\ Universitas Tunas Pembangunan Surakarta \\ hariyani.kuncoro@gmail.com
}

\begin{abstract}
Community reading parks are one place to develop abilities and add to the treasury of knowledge from the books they read. One form of activities to develop the ability and understanding of the community towards the development of science that is always developing is one of them through a public library that is packaged through community reading park activities. This activity was attended by 5 participants of the trilogy reading studio and 5 RT leaders. The activity is in the form of material delivery and direct practice of the management skills of the Trilogy Reading Studio through the documentation and administration system. As for the addition of facilities and infrastructure facilities through the delivery of material, FGD (focus groub discussion) and concluding a joint discussion between the implementers of community service activities, the organizers of reading centers and the Rt. As well as the delivery of material from the resource person (the community service team) plus external speakers through a zoom meeting on internetbased publications through the SID web system (Village Information system). This activity results in:1. Skills training for reading center administrators through a system of documentation and administration running well. 2. Provide implementation in the form of modification of facilities and infrastructure to support reading, writing and playing activities in the appropriate public facilities (fasum) area. 3. Providing training for administrators of TriLogi Studio reading about internetbased publications through a web system owned by RT 03/27 Griya Winong Housing new 2, Ngringo.
\end{abstract}

Keyword: Reading, Article, Publication.

\begin{abstract}
Abstrak
Taman bacaan masyarakat adalah salah satu tempat untuk mengembangkan kemampuan dan menambah khasanah mengenai ilmu dari buku yang dibacanya. Salah satu bentuk kegiatan untuk mengembangkan kemampuan dan pemahaman masyarakat terhadap perkembangan ilmu yang selalu berkembang tersebut salah satunya melalui perpustakaan umum yang dikemas melalui kegiatan taman bacaan masyarakat. Kegiatan ini dihadiri 5 orang peserta pengurus sanggar baca trilogi dan 5 pemuka RT. Kegitan berupa penyampaian materi dan praktek langsung skill pengurus Sanggar baca Trilogi melalui sistem dokumentasi dan administrasi. Sedangkan untuk penambahan fasilitas sarana dan prasarana melalui penyampaian materi, FGD (focus groub discussion) dan diakhiri musyawarah bersama antara pelaksana kegiatan pengabdian masyarakat, pengurus sanggar baca dan Pemuka Rt. Serta penyampaian materi dari narasumber (tim pengabdian masyarakat) ditambah narasumber luar melalui zoom meeting mengenai publikasi berbasis internet melalui sistem web SID (sistem Informasi Desa). Kegiatan ini menghasilkan: 1. Pelatihan skill pada pengurus sanggar baca melalui sistem dokumentasi dan administrasi berjalan dengan baik. 2. Memberikan implementasi berupa modifikasi sarana dan prasarana pendukung kegiatan membaca, menulis dan bermain pada area fasilitas umum (fasum) yang sesuai. 3. Memberikan pelatihan pengurus sanggar Baca TriLogi mengenai publikasi berbasis internet melalui sistem web yang dimiliki RT 03/27 Perumahan Griya Winong baru 2, Ngringo.
\end{abstract}

Kata Kunci: Baca, Artikel , Publikasi. 


\section{Pendahuluan}

Pendidikan melalui sistem membaca merupakan salah satu komponen pendidikan yang wajib diajarkan di sekolah (forma), diluar sekolah (non Formal) dan ditunjang dengan keberadaan perpustakaan umum serta rumah baca (in formal) untuk mengembangkan kemampuan anak akan ilmu pengetahuan. Dalam pelaksanakan pembelajaran terhadap anak dapat tercapai secara sukses tidak hanya peran guru saja akan tetapi juga sumbangsih dari lingkungan (informal) yang medukung. Pembelajaran dikatakan berhasil apabila perubahan perilaku yang terjadi pada pengguna taman bacaan masyarakat mencapai tingkat optimal pada taraf perkembangan dan pertumbuhannya. Hal tersebut dapat dibentuk melalui kegiatan pembelajaran diluar sekolah diantaranya melalui taman bacaan masyarakat. Dalam sistem UU no 20 tahun 2003 pasal 1 aya 3 menerangkan "pendidikan informal adalah jalur pendidikan keluarga dan lingkungan"

Tempat bacaan yang baik memiliki desain yang sangat multiliterasi, hal ini dibuktikan dalam menjawab tututan zaman dan tantangan pendidikan. Menurut Yunus abiding (2015) "konsep multi literasi yaitu multi konteks, multi media dan multi budaya". Taman bacaan masyarakat saat ini sangat popular dibandingkan dengan perpustakaan yang ada disekolah, sanggar baca yang ada dimasyarakat umum memiliki daya tarik tersendiri dikarenakan dibarengi rasa senang akan kebebasan jam diluar sekolah yang memiliki peraturan tidak mengikat. Perpustakaan sekolah memiliki konsep dan sistem yang baku, sementara untuk taman baca bersifat tidak baku, hal ini juga berfungsi untuk melestarikan masyarakat, meningkatkan kualitas masyarakat itu sendiri dan juga menekankan hubungan kehidupan sosial, politik dan ekonomi masyarakat (Wina sanjaya,2006).

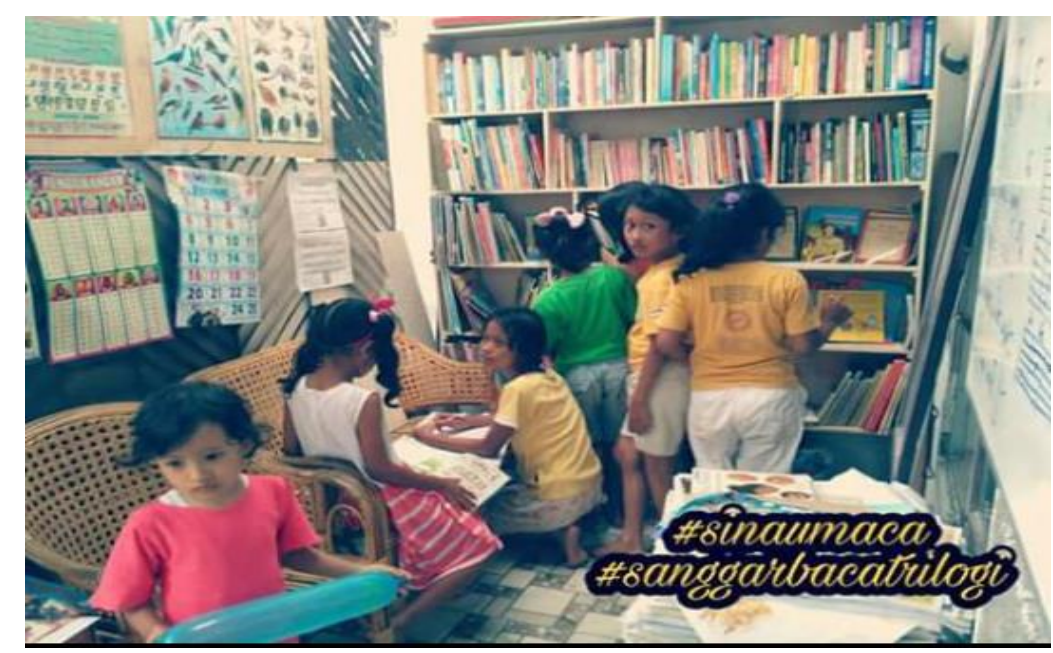

Gambar 1. Sanggar Baca Trilogi

Banyak warga pengunjung taman bacaan masyarakat, tidak memandang jenis kelamin, agama ataupun usia karena yang berminat dapat datang menggunakan taman bacaan masyarakat tersebut. Hal ini diperkuat Dewi S Prawiradilaga (2008) "pembaca adalah anda mulai dari pengajar,praktisi,mahasiswa atau pemerhati masyarakat". Dari hasil diskusi dengan warga Rt 3/27 dan pengelola sanggar baca maka dilakukan pertemuan demi kemajuan bersama. Masyarakat pun tertarik untuk mengikuti pengambangan taman bacaan yang mengarah pada sistem taman baca melalui fasilitas 
internet, hal ini juga belum banyak warga desa dijawa tengah dalam mengambangkan taman bacaan dan bisa dilakukan dengan metode yang sederhana dan praktis. Berdasar hasil observasi inilah Tim mengusulkan proposal pengabdian masyarakat untuk membantu memberikan sosialisasi serta pelatihan pembuatan tempat bacaan yang lebih menarik melalui sistem sanggar baca yang memiliki sistem adminstrasi dalam peminjaman buku dan pengembangan sistem berbasis internet serta menyediakan sarana prasarana yang ada.

Kegiatan pengabdian masyarakat ini bertujuan untuk meningkatkan kualitas kegiatan Taman Bacaan Masyarakat dengan penggunaan sarana dan prasarana yang memadai mengarah pada ruang ramah anak, Melatih skill administrasi dan publikasi yang baik agar menjadi komunitas yang lebih tertata (pelatihan pembuatan dokumentasi, penyusunan laporan kegiatan, pengkodingan buku dan sirkulasi peminjaman buku), pengembangan taman bacaan berbasis internet agar mampu berkembang lebih maksimal. Salah satu jenis kegiatan yang dilakukan oleh pengelola taman bacaan masyarakat sangatlah komplek mulai dari kegiatan membaca, menggambar, bermain, sampai pemahaman Bhinika tunggal ika dengan berlandaskan Pancasila. Pengguna taman bacaan tersebut dari berbagai usia, jenis kelamin maupun agama dengan mengedepankan kerukunan untuk meningkatkan Sumber daya manusia yang bermanfaat. akan tetapi dalam taman bacaan masyarakat tersebut masih jauh dari harapan maka sangatlah perlu memerlukan pendampingan secara menyeluruh. Mulai dukungan sarana prasarana, sistem administrasi yang baik serta pendampingan kegiatan secara tepat. Sehingga perlu dibentuk kelompok pengurus yang lebih kuat Menurut Todryk (dalam Scott dan Walker, 1995), keuntungan yang diperoleh dari pembentukan kelompok, yaitu meningkatkan kemampuan untuk merespon kebutuhan proyek, mampu merespon kebutuhan dengan lebih akurat, meningkatkan motivasi team, meningkatkan kekuatan team secara bersamaan, membawa proyek selesai tepat waktu, meningkatkan komitmen anggota team sebagai bagian dari team secara efektif.

Upaya untuk meningkatkan kualitas dan kwantitas taman bacaan dengan penerapan pengelolaan yang tepat dengan Teknologi Tepat Guna. Dalam kegiatan penerapan ipteks akan dilakukan pelatihan, pendampingan dan pemberian bantuan kepada pengelola taman bacaan masyarakat. Pola pendampingan tersebut salah satunya sistem administrasi. Menurut Way k Hoy dan cecil G miskel, dalam mussa aji (1998) "teori administrasi dibagi tiga tahapan sesuai perkembangannya pendekatan klasik, hubungan manusia, dan perilaku" Dengan demikian hendaknya dapat menerapkan teori tersebut agar bersinergi dengan harapan masyarakat untuk memperbaiki taman bacaan masyarakat dalam rangka untuk meningkatkan ilmu pengetahuan dan suber daya manusia utamanya masyarakat setempat. Hal ini dalam meningkatkan mutu sumberdaya manusia dalam suatu kelompok kerja maka perlu adanya kerja kelompok secara menyeluruh utamanya kohevisitas kerja kelompok Menurut Steer, dkk (1982), kohesivitas kerja kelompok itu mempengaruhi sikap pribadi individu-individu dalam hal (1) kepuasan kerja, (2) keterbukaan terhadap proses informasi bersama (social information processing), (3) ikatan pada organisasi kerja, misalnya kesetiaan, dorongan mengutamakan kepentingan bersama, dan sebagainya, sehingga meng-urangi "turnover", absentisme, 
ataupun kemalasan. Oleh karenanya, kohesivitas kerja dapat meningkatkan mutu SDM (sumber daya manusia) maupun produktivitas kelompok.

\section{Metode}

Berdasarkan permasalahan yang dihadapi Sanggar Baca Trilogi dalam mengembangkan usaha perpustakaan umum yang dikonsumsi oleh masyarakat luas. Kegitan berupa penyampaian materi dan praktek langsung skill pengurus Sanggar baca Trilogi melalui sistem dokumentasi dan administrasi. Sedangkan untuk penambahan fasilitas sarana dan prasarana melalui penyampaian materi, FGD (focus groub discussion) dan diakhiri musyawarah bersama antara pelaksana kegiatan pengabdian masyarakat, pengurus sanggar baca dan Pemuka Rt. Serta penyampaian materi dari narasumber (tim pengabdian masyarakat) ditambah narasumber luar melalui aplikasi zoom meeting mengenai publikasi berbasis internet melalui sistem web SID (sistem Informasi Desa). Kegiatan Program Kemitraan Masyarakat ini akan dilakukan melalui beberapa tahapan untuk mencapai tujuan kegiatan pemecahan masalah yang telah ditetapkan.

\section{Hasil dan Pembahasan}

Kegitan berupa penyampaian materi dan praktek langsung skill pengurus Sanggar baca Trilogi. Peserta dibagi dalam 2 kelompok terdiri dari 5 orang anggota. Lokakarya praktek langsung setelah diberikan penjelasan oleh tim pemateri pengabdian masyarakat dari Universitas Tunas Pembangunan Surakarta.

1. Skill pengurus Sanggar baca Trilogi melalui sistem dokumentasi dan administrasi.

Kegiatan presentasi melalui wujud pemberian materi skill pengurus Sanggar baca Trilogi melalui sistem dokumentasi dan administrasi bertempat di Sanggar Baca Trilogi, dimana Pemateri menyampaikan teknis secara tepat bagaimana cara menyusun sistem dokumentasi dan administrasi secara tepat. Dalam hal ini banyak sekali beberapa masalah yang harus diselesaikan, maka perlu adanya musyawarah bersama dalam menyelesaikan sedikit permaslahan yang ada di Sanggar Baca Trilogi. Melalui sistem presentasi, musyawarah kemudian dikaji ulang melalui teori administrasi dan dokumntasi yang dapat diterapkan, sehingga melalui sistem administrasi dan dokumentasi berdasarkan kajian teori yang diperoleh pengurus mengaplikasikan langsung dengan sistem praktek bagaimana penataan dokumentasi dan administrasi secara tepat.



Gambar 2. grafik tingkat pemahaman pelatihan sistem dokumentasi dan administrasi 
2. Skill pengurus Sanggar baca Trilogi melalui sistem publikasi berbasis internet.

Kegiatan ini berlangsung di Balai Srawung warga (BSW), bertempat di Fasilitas umum Rt 3/27 Perumahan Griya Winong Baru Ngringo, Jaten, Karanganganyar. Dalam kegiatan ini diawali kegiatan presentasi dari pemateri, kemudian dilanjut dengan kegiatan penguatan materi dari salah satu pengajar dari Sanata Dharma (pak Leo) melalui sistem aplikasi zoom meeting. Dipilih pak leo sebagai narasumber sekunder karena beliu sering kali mengunggah penulisan dalam bentuk artikel ataupun opini di surat kabar baik cetak maupun elektronik.

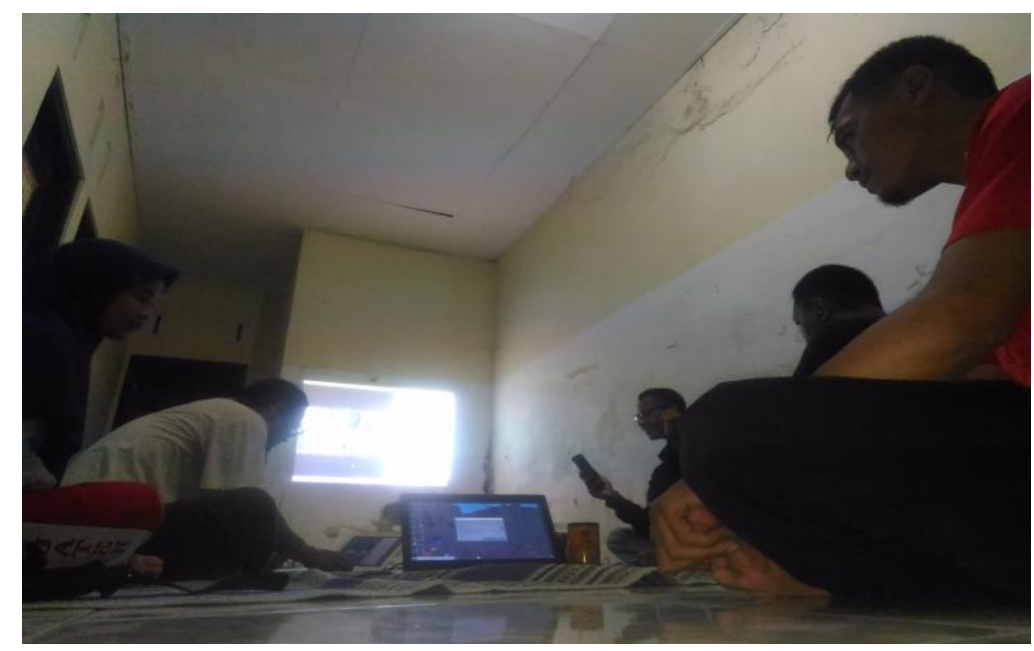

Gambar 3. pelatihan Skill pengurus melalui sistem publikasi berbasis internet

dalam kegiatan ini diikuti oleh pengurus dan pemuka masyarakat. Karena tujuan dari kegiatan lokakarya ini adalah agar pengurus dan pemuka masyarakat dapat menulis artikel yang dapat di unggah ke dalam web yang dimiliki oleh Rt. Banyak sekali permasalahan karena dari pengurus dan pemuka masyarakat mayoritas masih muda dan belum paham benar dengan pembuatan artikel. Melalui sistem lokakarya, teknis implementasi dikerjakan dirumah masing-masing, dengan menerapkan teknis penulisan yang dapat dipublikasikan di web Rt secara tepat.

\section{PENGURU SANGGAR BACA DAN PEMUKA RT BERJUMLAH 10 ORANG}

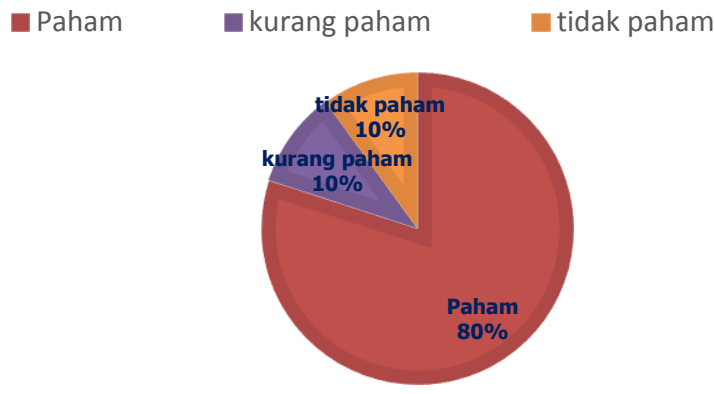

Gambar 4. grafik tingkat pemahaman lokakarya sistem publikasi berbasis internet. 
3. Implementasi modifikasi sarana dan prasarana pendukung kegiatan membaca, menulis dan bermain.

Penerapan implementasi ini merupakan kegiatan yang paling membutuhkan waktu dan diskusi secara sederhana. Teknis pelaksanaan ini bertempat di area diskusi Rumah makan Janti Klaten. Dimana dihasilkan secra musyawarah bahwa banyak anak sangat minim sekali fasilitas umum yang dapat digunakan untuk area belajar dan membaca buku khususnya. Sehingga hasil dari musyawarah ini diteruskan dalam wujud FGD (focus groub discussion) antara pelaksana pengabdian masyarakat, pemuka Rt dan pengurus sanggar baca.

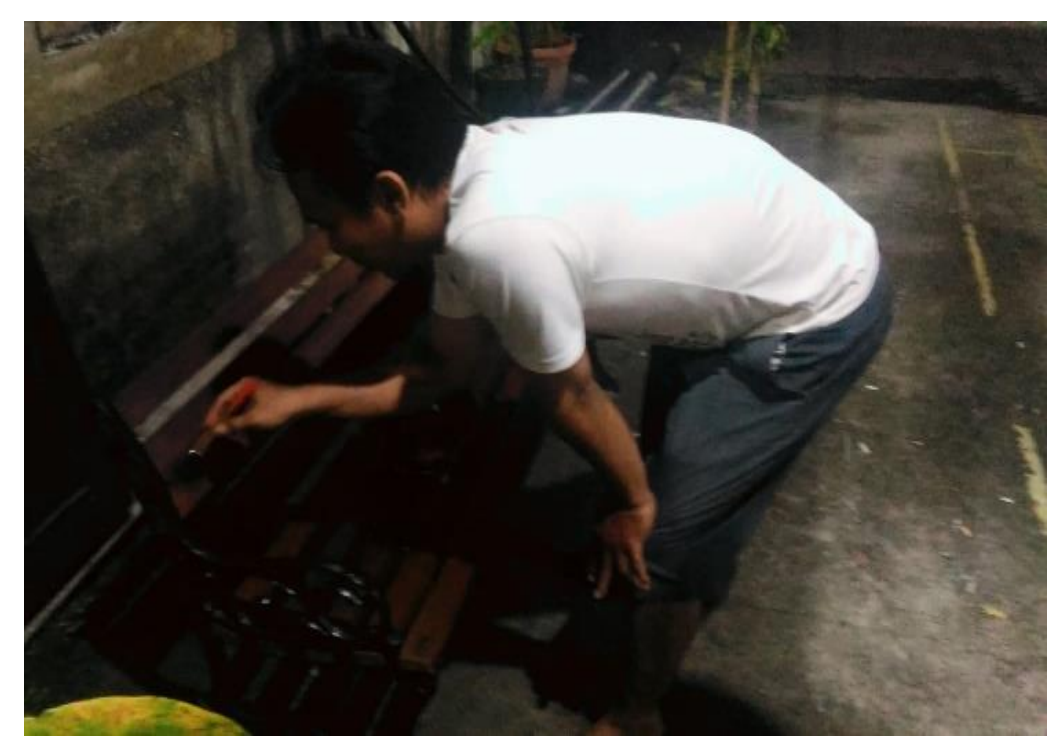

Gambar 5. Pengerjaan modifikasi sarana dan prasarana pendukung kegiatan belajar dan bermain

Karena minimnya fasilitas utamanya tempat duduk maka perlu adanya modifikasi tempat duduk yang menarik, nyaman dan anak khususnya sebagai pengguna lebih senang dalam menempatinya. Maka dipilihlah modifikasi kursi taman yang diletakkan pada fasilitas umum untuk menunjang proses belajar dan membaca masyarakat umum.

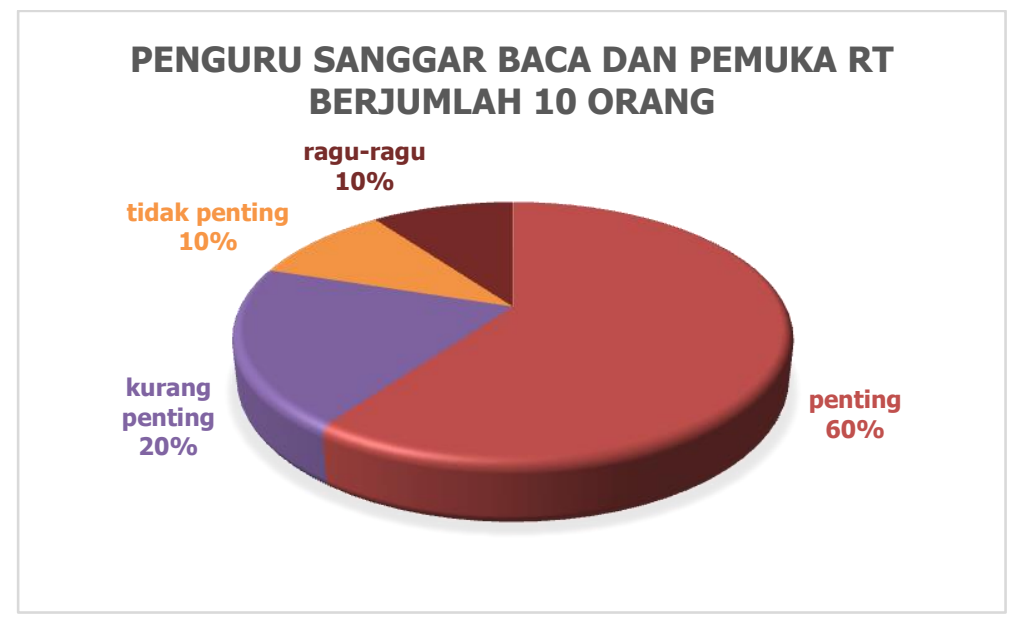

Gambar 6. Grafik prosentase modifikasi tempat belajar dan bermain 
Berikut faktor pendukung dan faktor penghambat kegiatan pengabdian masyarakat pada sanggar baca trilogi:

1. faktor mendukung: besarnya minat dan antusiasme peserta selama kegiatan, sehingga kegiatan berlangsung dengan lancar dan efektif.

Faktor penghambat: keterbatasan waktu implementasi dan pelatihan skill serta masih kurangnya ketersediaan sarana dan prasarana penunjang lain untuk merealisasikan hasil kegiatan pasca kegiatan pengabdian masyarakat ini.

\section{Kesimpulan}

Dari kegiatan pengabdian pada masyarakat ini dapat disimpulkan bahwa:

1. Pelatihan skill pada pengurus sanggar baca melalui sistem dokumentasi dan administrasi berjalan dengan baik.

2. Memberikan implementasi berupa modifikasi sarana dan prasarana pendukung kegiatan membaca, menulis dan bermain pada area fasilitas umum (fasum) yang sesuai.

3. Memberikan pelatihan pengurus sanggar Baca TriLogi mengenai publikasi berbasis internet melalui sistem web yang dimiliki RT 03/27 Perumahan Griya Winong baru no 2, Ngringo, Jaten, Karanganyar berjalan dengan lancar.

\section{Daftar Pustaka}

Abidin, Y. (2015). Pembelajaran Multu literasi, Bandung: Refika adit.

Prawiradilaga, D.S. (2008). Prinsip desain pembelajaran, Jakarta: Fajar inter pratama.

Mohhamad ali. (2015). Ilmu dan aplikasi Media, Bandung: Imtima.

Steer, dkk. 1982. Employee Organization Linkages: The Psychology of Commitment, Absenteism, and Turnover. New york. Academic Press

Sukarno. (2003). UU SISTEM PENDIDIKAN NASIONAL. Jakarta: Sekala Jalmakarya.

Scott \& Walker. 1995. TEAMS: Teamwork and Team Building. Singapure. Prentice-Hall, Inc.p 70

Sanjaya, W. (2006). Pembelajaran dalam Implementasi KBK, Jakarta: Prenada Media. 